\title{
Upregulation of Brain Renin Angiotensin System by 27-Hydroxycholesterol in Alzheimer's Disease
}

\author{
Laura Mateos $^{\mathrm{a}, *}$, Muhammad-Al-Mustafa Ismail ${ }^{\mathrm{a}}$, Francisco-Javier Gil-Bea ${ }^{\mathrm{a}}$, Valerio Leoni ${ }^{\mathrm{b}}$, \\ Bengt Winblad ${ }^{\mathrm{a}}$, Ingemar Björkhem ${ }^{\mathrm{c}}$ and Angel Cedazo-Mínguez ${ }^{\mathrm{a}, *}$ \\ ${ }^{a}$ Department of Neurobiology, Care Sciences and Society, Karolinska Institutet-Alzheimer's Disease \\ Research Center, NOVUM, Stockholm, Sweden \\ ${ }^{\mathrm{b}}$ Division of Biochemistry and Genetics, National Institute of Neurology Carlo Besta, Milano, Italy \\ ${ }^{\mathrm{c}}$ Department of Laboratory Medicine, Division of Clinical Chemistry, Karolinska University Hospital, \\ Huddinge, Sweden
}

Handling Associate Editor: Miia Kivipelto

Accepted 2 January 2011

\begin{abstract}
In spite of the fact that cholesterol does not pass the blood-brain barrier (BBB), hypercholesterolemia has been linked to increased Alzheimer's disease (AD) risk. Hypertension is another risk factor and angiotensin converting enzyme (ACE) activity is known to be increased in $\mathrm{AD}$. Furthermore, a lower incidence of $\mathrm{AD}$ has been reported in patients taking anti-hypertensive drugs. Here we show that the levels of angiotensinogen (AGT) and ACE are increased in the cerebrospinal fluid (CSF) of patients with mild cognitive impairment and AD. Moreover, we show ACE activity in the CSF to be positively correlated with both plasma and CSF levels of 27-hydroxycholesterol $(27-\mathrm{OH})$, an oxysterol known to pass through the BBB and taken up from the circulation by the brain. In addition, treatment of rat primary neurons, astrocytes, and human neuroblastoma cells with $27-\mathrm{OH}$ resulted in increased production of AGT. Our results demonstrate that upregulation of renin-angiotensin system (RAS) in AD brains occurs not only at the enzymatic level (ACE) but also at the substrate level (AGT). The possibility that 27-OH is part of a mechanism linking hypercholesterolemia with increased brain RAS activity and increased AD risk is discussed.
\end{abstract}

Keywords: Angiotensin I/II, angiotensinogen, cholesterol, 24-hydroxycholesterol, mild cognitive impairment, neurodegeneration

\section{INTRODUCTION}

Alzheimer's disease (AD) is the most notable dementia-associated neurodegenerative disorder. Despite age being the most important determinant for the disease, it is largely considered a multi-factorial disor-

\footnotetext{
*Correspondence to: Laura Mateos and Angel Cedazo-Mínguez Department of Neurobiology, Care Sciences and Society, Karolinska Institutet-Alzheimer's Disease Research Center, NOVUM, 5th Floor, SE-14186 Stockholm, Sweden. Tel.: +46 858583751 . Fax: +46 8585 83880; E-mail: Angel.Cedazo-Minguez@ki.se or Laura.Mateos-Montejo@ki.se..
}

der and several risk factors are likely to contribute to the probability of developing $\mathrm{AD}[1,2]$. An association between circulating cholesterol levels, cardiovascular disease, and hypertension with AD risk have been demonstrated in previous studies [3]. Although several epidemiological studies confirm the observation of increased incidence of $\mathrm{AD}$ with hypercholesterolemia [4] and increased blood pressure [5], the underlying mechanisms are still unknown.

The Renin-Angiotensin system (RAS), critically important for the regulation of blood pressure, is expressed in several tissues. A complete and functional 
RAS is also present in the brain and is independent from the RAS of renal origin [6]. Angiotensinogen (AGT), synthesized by glial cells as well as neurons [7], is converted into the inactive decapeptide angiotensin I (AngI) by the action of renin. Angiotensin converting enzyme (ACE), the principal effector of RAS, further converts AngI to angiotensin II (AngII) that acts on angiotensin II type 1 and 2 receptors (AT1R and AT2R). In addition to the classical functions on salt and water homeostasis and regulation of blood pressure, the RAS that is present in the central nervous system (CNS) appears to participate in the regulation of multiple brain functions including processing of sensory information, learning, memory, and emotional responses [8]. Several pathological processes such as stroke, depression, and emotional stress, as well as AD, have been suggested to be associated with dysregulation of the brain RAS [9]. Increased ACE activity has been demonstrated in different brain regions as well as in CSF of patients with $\mathrm{AD}[10,11]$. Furthermore, polymorphisms in the ACE gene are known susceptibility factors for AD [12, 13]. Moreover, AT1R [14] and AT2R [15] have also been found to be increased in AD cortex suggesting an augmented brain RAS activity during the disease process. To further support the importance of RAS in AD, AT1R blockers and ACE inhibitors commonly used in the treatment of hypertension have been associated with lower incidence of clinically diagnosed $\mathrm{AD}$ and improved cognitive function [16].

In view of the fact that the blood-brain barrier (BBB) prevents the entry of plasma cholesterol to the brain [17], it is intriguing how high serum cholesterol levels influence the risk of AD. In animal models, a diet-induced hypercholesterolemia has been shown to contribute to the deposition of amyloid- $\beta$ (A $\beta$ ) [18] and tau hyperphosphorylation [19]. However, the mechanism by which hypercholesterolemia increases the risk for $\mathrm{AD}$ is not fully understood. In a recent study, we used cDNA microarrays to study the effects of a cholesterol-enriched high-fat diet (HFD) on gene expression in mice brain with the aim of identifying new cellular pathways linking hypercholesterolemia and neurodegeneration [20]. Some of the defined cholesterol-regulated genes were linked to AD pathology including ACE and Arginine Vasopressin (AVP). According to this study, cholesterol in the periphery appears to be of importance for the regulation of the brain RAS.

The homeostasis of cholesterol is maintained within the CNS by a slow conversion of brain cholesterol into the oxysterol 24S-hydroxycholesterol (24S-OH) that is capable of passing through the BBB [21]. Another sidechain oxidized oxysterol, 27-hydroxycholesterol (27$\mathrm{OH})$, mainly formed outside the brain, is also able to cross the BBB [22]. The uptake of this steroid from the periphery by the brain is quantitatively important [23, 24]. Cholesterol homeostasis appears to be disturbed in AD patients, with decreased $24 \mathrm{~S}-\mathrm{OH}$ and increased $27-$ $\mathrm{OH}$ levels in the brain [25]. Plasma levels of cholesterol and 27- $\mathrm{OH}$ are closely correlated and it seems likely that high levels of cholesterol in the circulation result in increased influx of 27-OH to the brain. Based on this, we have suggested that $27-\mathrm{OH}$ may be the missing link between hypercholesterolemia and AD [26].

In the present paper we investigate the effects of cholesterol and cholesterol metabolites (24S-OH and 27-OH) on the brain RAS. We therefore designed a combined approach including analysis of CSF and plasma samples from controls, progressive mild cognitive impairment (MCI), and $\mathrm{AD}$ patients, as well as in vitro experiments using rat primary neurons and astroglia cell cultures. Overall, our results are consistent with the idea that there is a mechanistic link between hypercholesterolemia and hypertension contributing to AD pathology and involving the activation of brain RAS by $27-\mathrm{OH}$.

\section{MATERIALS AND METHODS}

\section{Cerebrospinal fluid (CSF) studies}

CSF was collected for diagnostic purposes by lumbar puncture in polypropylene tubes, mixed gently to avoid gradient effects and centrifuged at 2000xg for $10 \mathrm{~min}$. Aliquots were stored at $-80^{\circ} \mathrm{C}$ until biochemical analysis.

The patients were referred to the Memory Clinic at Karolinska University Hospital (Huddinge, Sweden). In this cross-sectional study, we included three groups; control $(n=25-28)$, MCI patients $(n=8-10)$ and AD patients $(n=20-21)$. The control group consisted of individuals with subjective cognitive impairment. MCI patients were: (i) not demented; (ii) had subjective self and/or objective informant report of cognitive decline and impairment on objective cognitive tasks; (iii) had preserved basic activities of daily living, and minimal impairment in complex instrumental functions [27]. All the MCI patients used in this study developed $\mathrm{AD}$ within a 3-year period. The $\mathrm{AD}$ cases were diagnosed according to The Diagnostic and Statistical Manual of Mental Disorders-IV (DSM-IV) criteria. They were evaluated according to a standard comprehensive protocol including clinical examination, 
brain imaging (MRI and SPECT), electroencephalography (EEG), analyses of blood and CSF (including Total-Tau, Phospho-Tau and $A \beta_{1-42}$ ), and a detailed neuropsychological evaluation. The study was conducted under the guidelines of the Declaration of Helsinki and approved by the ethics committee of the Karolinska Institutet.

\section{Oxysterol levels determination}

Plasma and CSF levels of 24S-OH and 27-OH were assayed by isotope dilution-mass spectrometry as described previously [28]. One $\mathrm{ml}$ of plasma was required for the oxysterol assay. In order to optimize the analysis of the CSF, $10 \mathrm{ng}$ of $\left[{ }^{2} \mathrm{H}_{3}\right]-24 \mathrm{~S}-\mathrm{OH}$ and $10 \mathrm{ng}$ of $\left[{ }^{2} \mathrm{H}_{4}\right]-27-\mathrm{OH}$ were added to $500 \mu \mathrm{l}$ of $\mathrm{CSF}$ together with $10 \mu \mathrm{l}$ of butylhydroxytoluene $(5 \mathrm{mg} / \mathrm{ml})$ and $20 \mu \mathrm{l}$ of EDTA $(10 \mathrm{mg} / \mathrm{ml})$. Under the conditions employed, the limit of detection in the assay used for CSF $24 \mathrm{~S}-\mathrm{OH}$ and $27-\mathrm{OH}$ was about $0.2 \mathrm{ng} / \mathrm{ml}$.

\section{Measurement of ACE concentration in the cerebrospinal fluid}

The concentration of ACE in the CSF was measured by established enzyme-linked immunosorbent assay (ELISA) system (R \& D systems, Minneapolis, Minnesota, USA). We first tested samples at different dilutions $(1: 10,1: 5$, and $1: 2)$ using the calibrator diluent (RD6-45), to optimize the conditions and warranting the precision of the assay. We determined that the best dilution was 2 -fold ( $25 \mu \mathrm{l} \mathrm{CSF}$ samples $+25 \mu$ l diluent per well) since the concentration values obtained were proximate to the standard curve midpoint.

\section{Brain tissue preparation}

Postmortem brain material was obtained from the Brain Bank at Karolinska Institutet (Karolinska University Hospital, Huddinge, Sweden) with approval by the Human Ethics Committee of Karolinska University Hospital. Samples from temporal cortex from $4 \mathrm{AD}$ brains (two males, 79 and 89 years old; two females 76 and 80 years old) and three aged-matched controls (two males, 66 and 83 years old; one 83 years old female) were used for Immunohistochemistry. All brains had a postmortem delay between 24 and $48 \mathrm{~h}$. The AD cases had a Mini-Mental State Examination (MMSE) score between 2 and 15 and met the clinical diagnosis of probable AD (DSM-IV criteria) as well as definite AD according to the CERAD neuropathological criteria.
Brain samples were fixed in buffered $4 \%$ formaldehyde and embedded in paraffin.

\section{Immunohistochemistry}

Sections ( $7 \mu \mathrm{m}$ thick) were mounted onto Superfrost plus-glass (Menzel Braunschweig, Germany). Unspecific binding was blocked by $5 \%$ normal goat serum (Sigma-Aldrich, St. Louis, MO, USA) in PBS for 30 min before incubation with the anti-AGT antibody (Abbiotec, CA, USA) diluted in PBS with $1 \%$ BSA overnight at $4{ }^{\circ} \mathrm{C}$. The sections were rinsed in PBS and incubated with biotinylated goat $\mathrm{IgG}$ for $2 \mathrm{~h}$ at room temperature. Rinsed in PBS between steps, the sections were incubated with avidin-biotin-peroxidase complex (Vectastain Elite ABC reagent, Vector Laboratories, CA, USA), exposed to diaminobenzidine (DAB) and mounted with mounting medium (DAKO Cytomation, Denmark). For control staining, the primary antibody was omitted.

\section{Cell cultures and treatments}

Cortical tissue from 18-day-old Sprague-Dawley rat embryos were homogenized in neurobasal medium supplemented with of 2\% B27 (Invitrogen, Sweden). Cells from each embryo were seeded separately in dishes, pre-coated with $0.17 \mathrm{mg} / \mathrm{ml}$ poly-D-lysine MW 300,000 (Sigma-Aldrich, Sweden) in PBS. Cerebellum from 18-day-old Sprague-Dawley rat embryos were mechanically dissociated and seeded in Dulbecco's modified Eagles medium (DMEM/F12) containing $10 \%$ fetal bovine serum (FBS) for the preparation of rat primary astrocyte cultures as previously described [29]. Cells were plated in dishes with poly-D-lysine (Sigma-Aldrich, Sweden). Cultures were kept at $37^{\circ} \mathrm{C}$ in a moist atmosphere $(95 \%$ air $/ 5 \% \mathrm{CO}_{2}$ ). Culture media were replaced twice a week.

Fourteen-day-old cultures were used for all experiments. At this time, astrocytes dominated as identified by immunocytochemical characterization [29]. Cultures used for the experiments contained on average $300,000 \pm 10,000$ cells per well. Most cells were flat, resembling inactivated astrocytes. Ethical consent for experiments with primary cultures was received from the regional ethical committee of Karolinska Institutet.

Neuroblastoma SH-SY5Y cells were cultured at $37^{\circ} \mathrm{C}, 5 \% \mathrm{CO}_{2}$, in Eagle's Minimum essential medium with Glutamax containing 10\% FBS (Sigma-Aldrich, Sweden). Treatments with 27-OH (Steraloids, Newport, Rhode Island, USA) were done at 1 or $10 \mu \mathrm{M}$ for 
Table 1

Demographic, clinical and biochemical characteristics of control, MCI and AD patients. Values are represented as mean $\pm \operatorname{SEM}\left({ }^{* *} p<0.01,{ }^{*} p<0.05\right)$

\begin{tabular}{lccc}
\hline & Control & MCI & AD \\
\hline Demographic & & & \\
$n$ & $25-28$ & $8-10$ & $20-21$ \\
Gender (male/female) & $9 / 19$ & $7 / 3$ & $7 / 14$ \\
Age & $57.81 \pm 1.27$ & $61.2 \pm 2.33$ & $67.3 \pm 1.70^{*}$ \\
Education (years) & $14.38 \pm 0.60$ & $12.33 \pm 1.43$ & $10.50 \pm 0.82$ \\
ApoE4 carrier $(\%)$ & 33.33 & 67.60 & 64.28 \\
MMSE & $29 \pm 0.21$ & $28.1 \pm .0 .28$ & $24.05 \pm 0.86^{* *}$ \\
Plasma & & & \\
Cholesterol $(\mathrm{g} / \mathrm{L})$ & $2.22 \pm 0.06$ & $2.30 \pm 0.05$ & $2.25 \pm 0.07$ \\
24S-OH $(\mu \mathrm{g} / \mathrm{L})$ & $56.30 \pm 1.80$ & $49.73 \pm 1.67^{*}$ & $48.45 \pm 2.64^{*}$ \\
27-OH $(\mu \mathrm{g} / \mathrm{L})$ & $223.69 \pm 10.30$ & $181.5 \pm 16.60^{*}$ & $174.28 \pm 11.34^{* *}$ \\
HDL $(\mathrm{mM} / \mathrm{L})$ & $1.57 \pm 0.06$ & $1.86 \pm 0.07$ & $1.58 \pm 0.08$ \\
LDL $(\mathrm{mM} / \mathrm{L})$ & $3.58 \pm 0.14$ & $3.63 \pm 0.14$ & $3.43 \pm 0.15$ \\
CSF & & & \\
Total tau $(\mathrm{ng} / \mathrm{L})$ & $278.70 \pm 27.39$ & $471.4 \pm 83.81^{*}$ & $626.6 \pm 80.96^{* *}$ \\
P-tau $(\mathrm{ng} / \mathrm{L})$ & $54 \pm 4.73$ & $69.5 \pm 14.17$ & $88.7 \pm 9.26^{* *}$ \\
A $\beta_{42}(\mathrm{ng} / \mathrm{L})$ & $760.96 \pm 40.43$ & $423.37 \pm 24.44^{*}$ & $536.13 \pm 41.16^{* *}$ \\
ApoE $(\mu \mathrm{g} / \mathrm{L})$ & $3.73 \pm 0.25$ & $3.65 \pm 0.39$ & $4.16 \pm 0.30$ \\
Cholesterol $(\mathrm{mg} / \mathrm{L})$ & $2.75 \pm 0.14$ & $2.81 \pm 0.23$ & $3.04 \pm 0.15$ \\
CSF 24S-OH $(\mu \mathrm{g} / \mathrm{L})$ & $2.69 \pm 0.15$ & $3.25 \pm 0.29$ & $3.39 \pm 0.40$ \\
CSF 27-OH $(\mu \mathrm{g} / \mathrm{L})$ & $0.37 \pm 0.04$ & $0.46 \pm 0.10$ & $0.59 \pm 0.07^{*}$ \\
ACE $(\mathrm{ng} / \mathrm{ml})$ & $3.58 \pm 0.21$ & $4.41 \pm 0.21^{*}$ & $4.27 \pm 0.27^{*}$ \\
\hline
\end{tabular}

$24 \mathrm{~h}$. Subsequent to treatments, cells were collected and lysed in a lysis buffer $(50 \mathrm{mM}$ Tris- $\mathrm{HCl}, 150 \mathrm{mM}$ $\mathrm{NaCl}, 2$ mM EDTA, 2 mM EGTA, 1\% Triton-X100) containing protease inhibitor and phosphatase inhibitor cocktails (Sigma-Aldrich, Sweden).

\section{Immunoblotting}

Equal amounts of proteins were separated using $10 \%$ acrylamide gel and later transferred to a nitrocellulose membrane (Schleicher \& Schuell, Germany). The blots were incubated with AGT antibody (Abbiotec, CA, USA), angiotensin (N-10) antibody (Santa Cruz Biotechnology, CA, USA) or actin antibody (Sigma Aldrich, Sweden). The angiotensin (N-10) antibody recognizes both AngI and AngII, which result from the consecutive cleavage of AGT by renin and ACE, respectively. Incubation with primary antibodies were performed overnight at 1:1000 dilution, followed by incubation with anti-rabbit or anti-mouse $\mathrm{IgG}$ at 1:5000 dilution (Amersham Biosciences, Little Chalfont, England). Immunoreactivity was detected by the ECL detection system (Amersham Biosciences, Little Chalfont, England). Some immunoblots were stripped using Restore ${ }^{\mathrm{TM}}$ Western Blot Stripping buffer (Pierce, Rockford, IL, USA) at room temperature for $15 \mathrm{~min}$. The relative densities of the immunoreactive bands were calculated from the optical density (OD) of the selected area using ImageJ $1.37 \mathrm{v}$ software $(\mathrm{NIH}$, MA, USA).

\section{Statistical analysis}

Results are expressed as a mean \pm SEM. Normality was checked by Shapiro-Wilks test before any further statistical analysis. An analysis of covariance (ANCOVA) with age and gender as the covariate was used to compare differences in biochemical measurements between control, MCI and AD patients. Partial correlations with age, gender, and grouping effect as confounding variables were used to assess associations between biochemical and clinical variables of patients. Results from in vitro experiments were analyzed by Student's $t$ test. A value of $p<0.05$ was considered statistically significant in all analyses.

\section{RESULTS}

Correlation of cholesterol and 27-OH with members of the Renin-Angiotensin System in Alzheimer's disease patients

The demographic, clinical and biochemical characteristics of the subjects enrolled in our study are shown in Table 1. AD patients were observed to be significantly older than the controls $\left(F_{(2,58)}=8.33, p<0.05\right)$. 

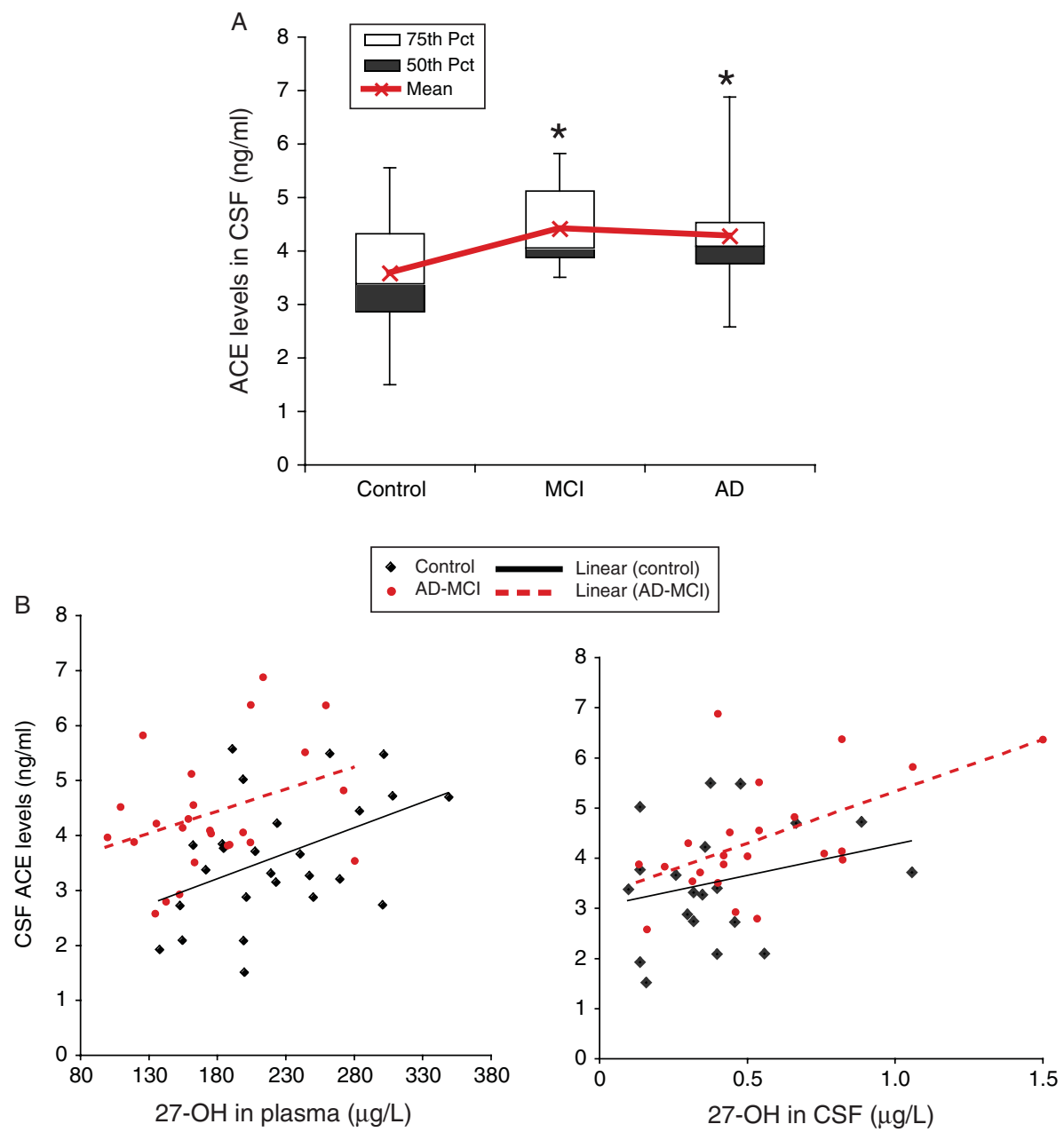

Fig. 1. Correlation between ACE and 27-OH levels in MCI and AD. A) ACE concentrations in CSF from control, MCI, and AD cases. Vertical box histogram shows the quantification of ACE $(\mathrm{ng} / \mathrm{ml})$ obtained by established enzyme-linked immunosorbent assay (ELISA) system $\left({ }^{*} p<0.05\right.$ vs. Control). B) Correlations between levels of ACE and plasma 27-OH (for AD-MCI group: $r=0.34, p<0.05$; left panel) and CSF 27-OH (for AD-MCI group: $r=0.49, p<0.01$; right panel). C: Control, AD: Alzheimer's disease.

Due to this age difference, we examined the results following the correction for age and gender. Clinically, it was observed that AD patients presented with a significantly lower MMSE score $\left(F_{(2,58)}=14.79\right.$, $p<0.01)$ than the controls. However, in regards to the characteristics of $\mathrm{AD}$, the CSF total tau (T-tau) $\left(F_{(2,56)}=7.89, p<0.01\right)$ and CSF phosphorylated-tau (p-tau) $\left(F_{(2,51)}=4.00, p<0.01\right)$ levels were higher than the controls in AD patients. Additionally, the levels of CSF A $\beta_{1-42}\left(F_{(2,53)}=8.82, p<0.01\right)$ were observed to be lower in both AD and MCI cases.

In agreement with previous studies [28], CSF levels of 27-OH in AD patients were found to be higher $\left(F_{(2,44)}=3.31, p<0.05\right)$ while $24 \mathrm{~S}-\mathrm{OH}$ showed an augmented trend $\left(F_{(2,51)}=1.93, p=0.16\right)$ with respect to the control group. The plasma levels of $27-\mathrm{OH}$ $\left(F_{(2,53)}=7.41, p<0.01\right)$ and $24 \mathrm{~S}-\mathrm{OH}\left(F_{(2,53)}=4.34\right.$, $p<0.05)$ were found to be significantly lower in AD and MCI individuals when compared to controls as expected [28]. Cholesterol levels in both plasma and CSF displayed no significant changes between controls, AD or MCI patients.

As previously reported [11], ACE levels measured by ELISA in the CSF were significantly higher in MCI and AD patients $\left(F_{(2,54)}=3.15, p<0.05\right)$ than controls (Table 1 and Fig. 1A). Interestingly, an association between 27-OH and CSF-ACE was clearly observed. Both the plasma and CSF levels of 27$\mathrm{OH}$ were positively correlated with CSF ACE in AD $(r=0.34, p<0.05, n=20$ for plasma-AD; $r=0.49$, 
Table 2

Correlations between levels of total cholesterol, 27-OH and 24S-OH (in plasma and CSF), and CSF biochemical markers for AD as well as cognitive score. Table shows correlations in the AD-MCI group. Age, gender, and grouping effect were used as confounding variables

\begin{tabular}{|c|c|c|}
\hline & $r$ & $p$-value \\
\hline $\mathrm{CSF} 24 \mathrm{~S}-\mathrm{OH}$ vs $\mathrm{CSF} \mathrm{A} \beta_{42}$ & -0.145 & 0.16 \\
\hline CSF 24S-OH vs CSF T-tau & 0.468 & $<0.01^{* *}$ \\
\hline CSF 24S-OH vs CSF p-tau & 0.535 & $<0.01^{* *}$ \\
\hline CSF $24 \mathrm{~S}-\mathrm{OH}$ vs MMSE & 0.103 & 0.24 \\
\hline Plasma 24S-OH vs CSF A $\beta_{42}$ & -0.07 & 0.33 \\
\hline Plasma 24S-OH vs CSF T-tau & -0.16 & 0.14 \\
\hline Plasma 24S-OH vs CSF p-tau & -0.09 & 0.28 \\
\hline Plasma 24S-OH vs MMSE & -0.04 & 0.38 \\
\hline $\mathrm{CSF} 27-\mathrm{OH}$ vs $\mathrm{CSF} \mathrm{A} \beta_{42}$ & -0.06 & 0.35 \\
\hline CSF 27-OH vs CSF T-tau & 0.22 & $0.05^{*}$ \\
\hline CSF 27-OH vs CSF p-tau & 0.15 & 0.17 \\
\hline CSF 27-OH vs MMSE & -0.07 & 0.33 \\
\hline Plasma 27-OH vs CSF A $\beta_{42}$ & 0.30 & $<0.05^{*}$ \\
\hline Plasma 27-OH vs CSF T-tau & -0.09 & 0.27 \\
\hline Plasma 27-OH vs CSF p-tau & 0.05 & 0.37 \\
\hline Plasma 27-OH vs MMSE & -0.02 & 0.45 \\
\hline CSF Chol vs CSF $\mathrm{A}_{42}$ & 0.25 & 0.06 \\
\hline CSF Chol vs CSF T-tau & 0.26 & $<0.05^{*}$ \\
\hline CSF Chol vs CSF p-tau & 0.31 & $<0.05^{*}$ \\
\hline CSF Chol vs MMSE & 0.08 & 0.31 \\
\hline Plasma Chol vs CSF A $\beta_{42}$ & 0.11 & 0.25 \\
\hline Plasma Chol vs CSF T-tau & 0.19 & 0.11 \\
\hline Plasma Chol vs CSF p-tau & 0.17 & 0.15 \\
\hline Plasma Chol vs MMSE & 0.11 & 0.24 \\
\hline $\mathrm{CSF} 24 \mathrm{~S}-\mathrm{OH} / 27-\mathrm{OH}$ vs $\mathrm{CSF} \mathrm{A} \beta_{42}$ & -0.13 & 0.20 \\
\hline CSF 24S-OH/27-OH vs CSF T-tau & 0.03 & 0.44 \\
\hline $\mathrm{CSF} 24 \mathrm{~S}-\mathrm{OH} / 27-\mathrm{OH}$ vs CSF p-tau & 0.09 & 0.28 \\
\hline $\mathrm{CSF} 24 \mathrm{~S}-\mathrm{OH} / 27-\mathrm{OH}$ vs MMSE & 0.15 & 0.16 \\
\hline Plasma 24S-OH/27-OH vs CSF $\mathrm{A} \beta_{42}$ & -0.32 & $<0.05^{*}$ \\
\hline Plasma 24S-OH/27-OH vs CSF T-tau & -0.11 & 0.23 \\
\hline Plasma 24S-OH/27-OH vs CSF p-tau & -0.2 & 0.1 \\
\hline Plasma 24S-OH/27-OH vs MMSE & -0.06 & 0.34 \\
\hline
\end{tabular}

$r=$ correlation coefficient after correcting for grouping effect and age. ${ }^{*} p<0.05 ;{ }^{* *} p<0.01$.

$p<0.01, n=20$ for CSF-AD) but not with the controls after correcting for the confounding variables, i.e., age and gender (Fig. 1B). However, no correlation was observed between plasma/CSF levels of $24 \mathrm{~S}-\mathrm{OH}$ or cholesterol and the ACE levels in CSF.

Next we compared the levels of oxysterols and total cholesterol with pathological and clinical features of AD (Table 2). Here, we found after correcting for grouping effect and age, a correlation between the CSF levels of 24S-OH and CSF levels of both T-tau and ptau ( $r=0.47, p<0.01 ; r=0.54, p<0.01$ respectively). Moreover, the CSF levels of 27-OH and CSF T-tau $(r=0.22, p=0.05)$ in addition to the plasma levels of $27-\mathrm{OH}$ and CSF A $\beta_{1-42}$ levels $(r=0.30, p<0.05)$ were also seen to correlate. Cholesterol present in the CSF correlated with both T-tau and p-tau present in the CSF ( $r=0.26, p<0.05 ; r=0.31, p<0.05$ respectively). As for the level of $A \beta_{1-42}$ in the CSF, a correlation was observed with the ratio of $24 \mathrm{~S}-\mathrm{OH} / 27-\mathrm{OH}$ present in the plasma of $\mathrm{AD}$ patients.

\section{Increased levels of angiotensinogen (AGT) in MCI and $A D$ patients}

Levels of AGT and AngI/II were analyzed in CSF samples from controls, MCI and AD individuals by immunoblotting. As seen in Fig. 2A, AGT was significantly increased in the CSF of MCI and AD patients compared to controls. A trend towards increased levels of AngI/II was observed in AD patients (control $=100 \pm 20.46 ; \quad \mathrm{AD}=152.89 \pm 27.48)$, although these changes were not statistically significant.

Furthermore, immunohistochemical analysis revealed that, in control brains, AGT immunoreactivity was localized mostly in the cytosolic compartment of neurons (Fig. 2B). In AD brains, AGT was generally reduced in healthy looking neurons (determined according to Oppenheimer's criteria, including the central position of the nucleus and the presence of a single large conspicuous nucleolus) ("a" in Fig. 2B). However, an intense AGT immunoreactivity was found in some neurons with certain morphological phenotype resembling ghost neurons ("b" in Fig. 2B). Additionally, compared to controls, AD brains revealed an increased AGT immunoreactivity in glia-like profiles ("c" in Fig. 2B).

\section{7-OH enhances angiotensinogen production in cultured cells}

Since astroglia are thought to be the most important source of AGT in the brain [30], we tested the impact of $27-\mathrm{OH}$ on AGT production in rat primary astrocytes. Non-significant increase was found in the cellular levels of AGT protein in astrocytes exposed to 27-OH (data not shown). However, as shown in Fig. 3A (left panel), treatment of astrocytes with $27-\mathrm{OH}(1 \mu \mathrm{M})$ resulted in a significant increase in secreted levels of AGT protein ( $150 \%$ of control, $p<0.05)$. On the other hand, a higher concentration of $27-\mathrm{OH}(10 \mu \mathrm{M})$ caused a slight but non-significant increase on AGT production (Fig. 3A, right panel).

In rat primary neuronal cultures, both concentrations of $27-\mathrm{OH}(1 \mu \mathrm{M}$ and $10 \mu \mathrm{M})$ induced a significant increase on cellular levels of AGT (Fig. 3B). As seen in Fig. 3C this effect was also present in SH-SY5Y neuroblastoma cells.

\section{DISCUSSION}

In accordance to previous studies, our results showed that ACE levels in the CSF are increased in 
A
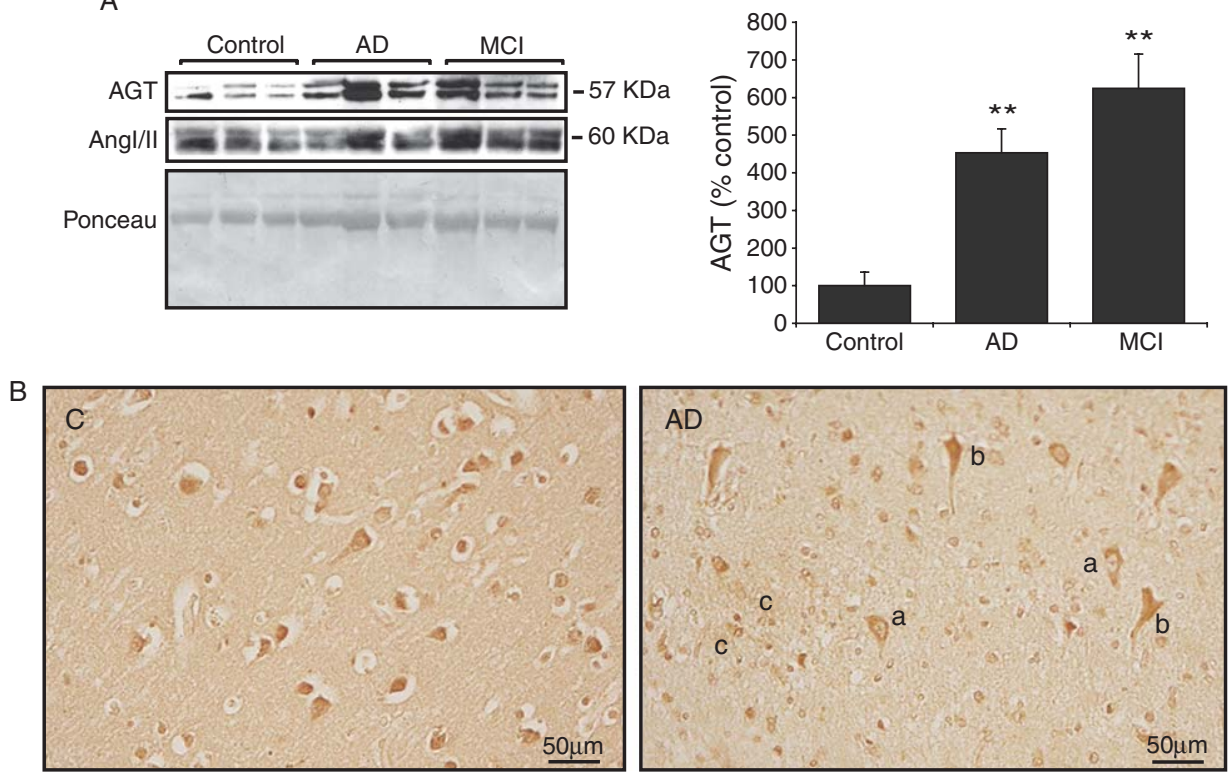

Fig. 2. Brain RAS is upregulated in AD and MCI. A) Immunoblots of CSF samples from control, AD and MCI cases using anti-AGT and Angiotensin (N-10) antibody. Ten $\mu \mathrm{l}$ of CSF from control, AD and MCI patients were loaded in each well. Ponceau staining was used as a loading control. Data were normalized as ratios to total protein levels. Histogram shows AGT data expressed as percentage of values for control patients. Data shown as mean $\pm \mathrm{SEM}\left({ }^{* *} p<0.01\right.$ vs. Controls). B) AGT Immunohistochemistry in cortical sections from one AD brain (female, 80 years old) and one control brain (female, 83 years old). In AD samples, AGT expression is decreased in healthy looking neurons ("a") and increased in glial-like profiles ("c"). In AD samples, an intense AGT immunoreactivity was found in some neurons with morphological phenotype resembling ghost neurons ("b"). Scale bars $=50 \mu \mathrm{m}$. C: Control, AD: Alzheimer's disease.

patients with $\mathrm{AD}$ and $\mathrm{MCI}$ after the correction for age and gender (Fig. 1A) [11]. However, our study demonstrates for the first time that another component of the brain RAS; AGT, is also increased in the CSF of these patients (Fig. 2A). This indicates that upregulation of brain RAS in AD does not only occur at the level of the enzymatic proteolysis (ACE activity) but also at the substrate level (AGT). Since AGT levels in CSF were also increased in progressive MCI (patients that will develop $\mathrm{AD}$ in 3 years time), our results suggest that RAS upregulation occurs early and not only in the final stages of the disease.

We analyzed the possibility that $27-\mathrm{OH}$ mediates the upregulation of brain RAS under in vivo conditions in humans. We found a significant correlation between the levels of 27-OH and ACE in the CSF from patients (MCI and AD) (Fig. 1B). However, a correlation did not exist between blood cholesterol and CSF-ACE. Similarly, levels of 24S-OH and ACE in the CSF were not correlated. It is well documented that the levels of 27-OH are increased in the CSF of patients with neurodegenerative diseases [31]; this was also confirmed in the present study (Table 1). The reason for the increase is not completely understood but it has been suggested that one factor of importance could be a relative deficiency of the metabolizing enzyme CYP7B1 [22]. Since this enzyme is located in neurons, neuronal damage may result in the impaired capacity to metabolize $27-\mathrm{OH}$.

It has been previously suggested that $27-\mathrm{OH}$ could play an active role in AD pathogenesis. Supporting this contention, we found a correlation between the levels of this oxysterol and features of AD such as CSF levels of $A \beta_{1-42}$, T-tau, and p-tau. We have previously shown that $27-\mathrm{OH}$ reduces the expression of the activity-regulated cytoskeleton-associated protein (Arc), a factor important for memory consolidation [20]. 27-OH has also been shown to antagonize the preventive effect of $24 \mathrm{~S}-\mathrm{OH}$ in the generation of $\mathrm{A} \beta$ [22] and to increase $A \beta$ production in neuronal preparations from adult rabbit brain [32]. Based on the results obtained in this study, it is suggested that increased 27-OH influx to the brain may activate brain RAS.

In an attempt to clarify as to whether the above findings really refer to a potential role for the metabolism of cholesterol in the modulation of the RAS system 

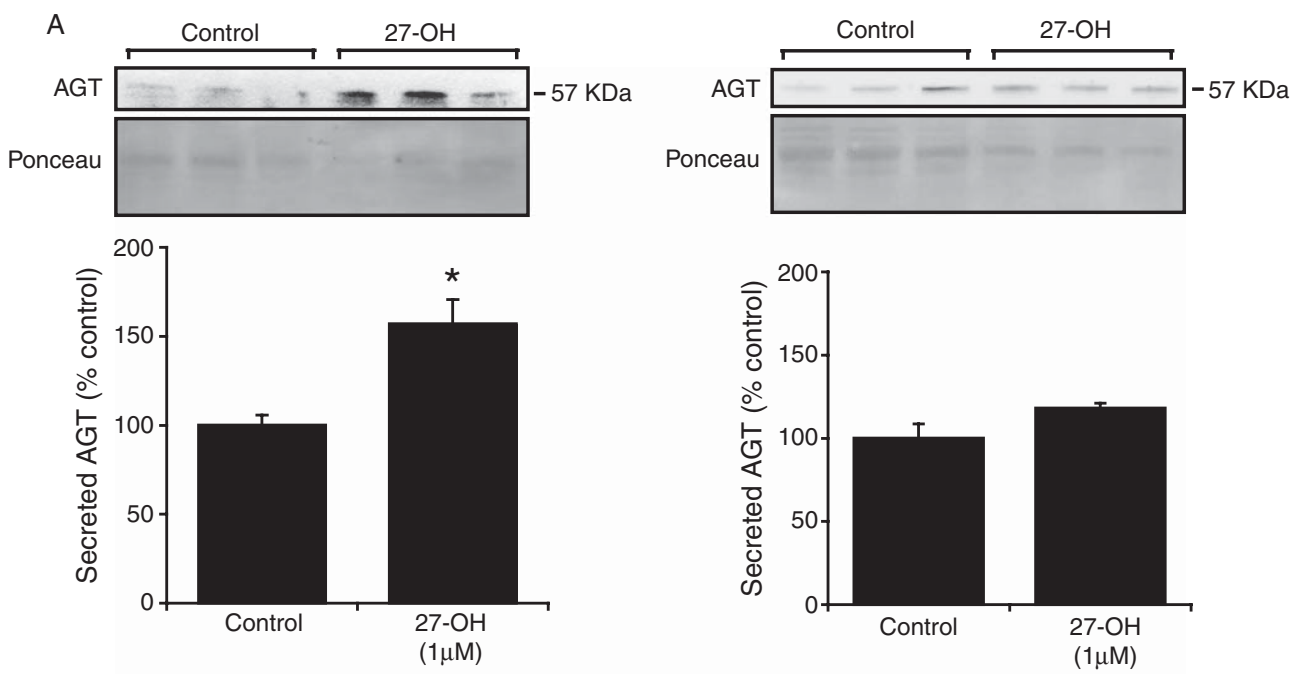

B
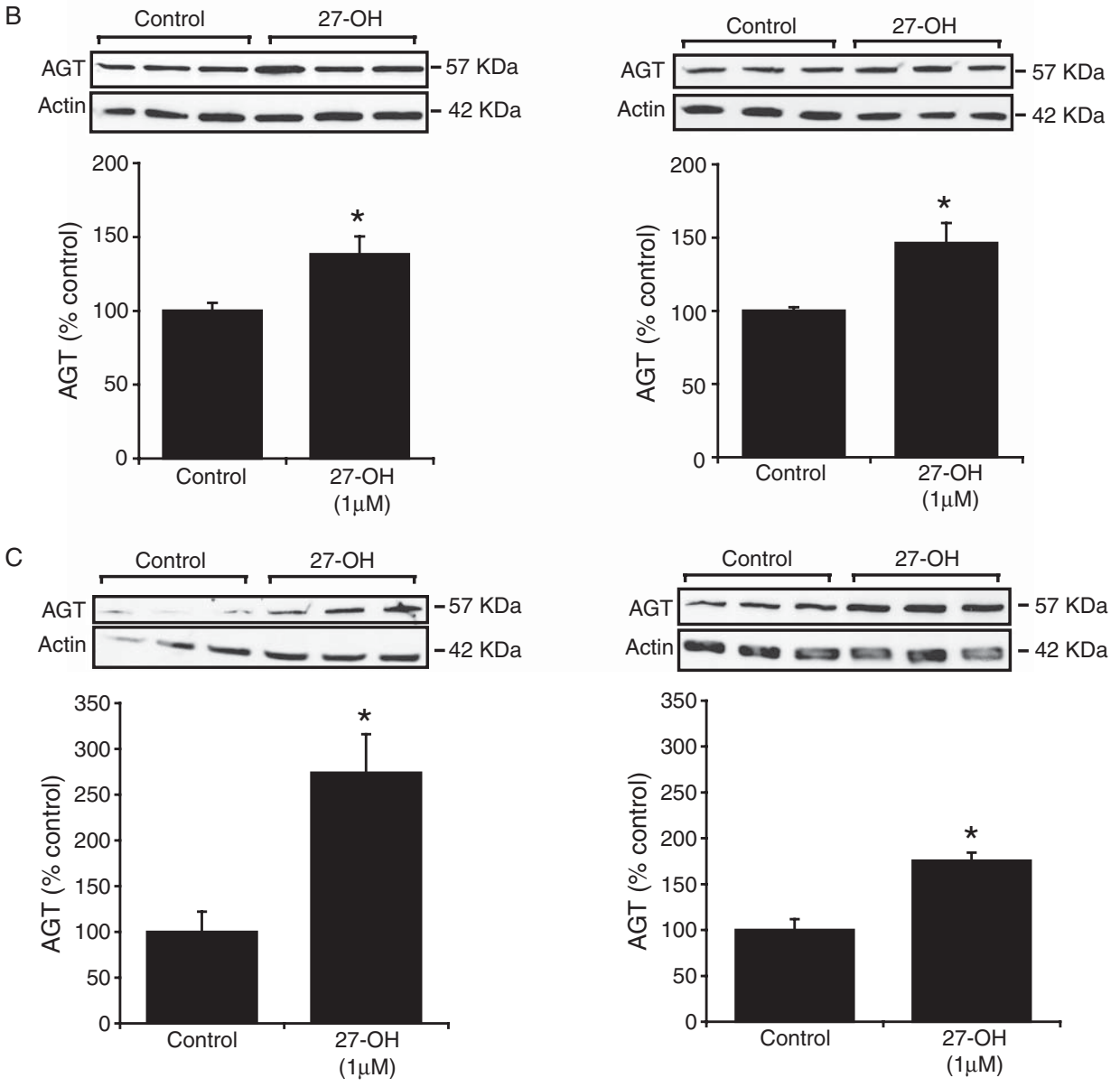

Fig. 3. 27-OH enhances AGT production in astrocytes and neurons. A) Media (100 $\mu \mathrm{l})$ from astrocytes treated with $27-\mathrm{OH}$ (1 $\mu \mathrm{M}$ and $10 \mu \mathrm{M} ; 24 \mathrm{~h}$ ) were immunoblotted with anti-AGT antibody. Ponceau staining was used as a loading control. At $1 \mu \mathrm{M}, 27-\mathrm{OH}$ was able to induce a significant increase on AGT secretion in astrocytes $\left({ }^{*} p<0.05 \mathrm{vs}\right.$. Control, left panel). B) Lysates from rat primary neurons treated with 27-OH ( $1 \mu \mathrm{M}$ and $10 \mu \mathrm{M} ; 24 \mathrm{~h})$ were immunoblotted with anti-AGT antibody. 27-OH induced a strong increase on AGT production at both concentrations ( ${ }^{*} p<0.05$ vs. Control). C) Human neuroblastoma SH-SY5Y cells treated with $27-\mathrm{OH}(1 \mu \mathrm{M}$ and $10 \mu \mathrm{M} ; 24 \mathrm{~h})$ and lysates immunoblotted with anti-AGT antibody. Data were normalized as ratios to total protein levels in the respective lysates (A) and to actin (B and C), and presented as mean \pm SEM. 
and not just to a single parallelism in the development of $\mathrm{AD}$ pathology, we next performed in vitro experimental studies by treating cells with $27-\mathrm{OH}$. In the brain, most AGT is produced by astrocytes. We found that 27-OH induced a significant increase in AGT production in rat astrocyte cultures, as evidenced by increased AGT levels present in conditioned media. An increase in AGT production was found also in treated neurons (rat primary cultures and human neuroblastoma cells), suggesting a general non-cell specific mechanism. However, in AD brains, we showed by immunohistochemistry an increased AGT immunoreactivity in glial cells and a decrease in healthy looking neurons. Therefore, a more complex disruption in AGT production/cleavage in the late stages of $\mathrm{AD}$ could be assumed. Nevertheless, the results of in vitro and in vivo experiments presented here are consistent with the assertion that an increased flux of $27-\mathrm{OH}$ into the brain is associated with an upregulation of the brain RAS in the course of AD.

Several studies have shown that cholesterol-enriched diet (HFD) induces cognitive deficits in mice $[33,34]$. ApoE-knockout mice fed with HFD revealed increased levels of 27-OH but unchanged levels of $24 \mathrm{~S}-\mathrm{OH}$ in the brain [35]. We recently showed that HFD induced changes in the expression of several genes in mice brains including ACE [20]. On the other hand, recent studies reported that transgenic mice expressing human renin and AGT genes (hRN/hAGT$\mathrm{Tg}$ ) have impaired cognition, increased oxidative stress in the brain, and ischemic brain damage mediated by overstimulation of AT1R [36, 37]. It is evident that brain RAS is important for a variety of neuronal functions as well as for the regulation of cerebral blood flow [38]. The effects of AngII mainly mediated by AT1R include vasoconstriction and vasopressin release in the brain [39] but it is also implicated in mechanisms that may be significant in AD such as transforming growth factor-beta signaling [40], BBB maintenance [41], and cell survival [42]. Accumulating data support the association of hypertension with declining cognitive function and dementia [43] while management of blood pressure with antihypertensive drugs is partially effective for the prevention of cognitive decline in older adults [44], including those with AD [45]. Furthermore, animal studies have shown that ACE inhibitors enhance cognitive performance [46] and improve learning and retention of memory [47]. These experiments have led to the hypothesis that ACE inhibitors facilitate cognitive processes by reduction of available AngII, which regulates cerebral blood flow by stimulating cerebral vasoconstriction via AT1R. Moreover, it has been reported that AT1R blockers attenuate ischemic brain damage [48]. On the other hand, RAS upregulation inducing the overstimulation of AT1R leads to cognitive deficits and ischemic damage in mice [36, 37]; as well as hypertension, vascular brain damage and insulin resistance in humans [49], known risk factors for AD [50].

In summary, the present results are consistent with the ideas that 1) the metabolism of peripheral cholesterol is of importance for the modulation of RAS in the brain, and 2) that $27-\mathrm{OH}$ may be a link between the neurodegenerative effects caused by high blood cholesterol levels and hypertension.

\section{ACKNOWLEDGMENTS}

This research was supported by grants from the following Swedish foundations: Swedish Brain Power, Riskbankens jubileumsfond, Gun och Bertil Stohnes Stiftelse, Karolinska Institutet fund for geriatric research, Stiftelsen Gamla Tjänarinnor, Swedish Research Council, Alzheimerfonden and the regional agreement on medical training and clinical research (ALF) between Stockholm County Council and the Karolinska Institutet. The study was conducted under the guidelines of the Declaration of Helsinki and approved by the ethics committee of the Karolinska Institutet.

Authors' disclosures available online (http://www. j-alz.com/disclosures/view.php?id=725).

\section{REFERENCES}

[1] Cedazo-Minguez A (2007) Apolipoprotein E and Alzheimer's disease: molecular mechanisms and therapeutic opportunities. J Cell Mol Med 11, 1227-1238.

[2] Kivipelto M, Rovio S, Ngandu T, Kareholt I, Eskelinen M, Winblad B, Hachinski V, Cedazo-Minguez A, Soininen H, Tuomilehto J, Nissinen A (2008) Apolipoprotein E epsilon4 magnifies lifestyle risks for dementia: a population-based study. J Cell Mol Med 12, 2762-2771.

[3] Kivipelto M, Helkala EL, Laakso MP, Hanninen T, Hallikainen M, Alhainen K, Soininen H, Tuomilehto J, Nissinen A (2001) Midlife vascular risk factors and Alzheimer's disease in later life: longitudinal, population based study. BMJ 322, 1447-1451.

[4] Whitmer RA, Gunderson EP, Barrett-Connor E, Quesenberry CP Jr, Yaffe K (2005) Obesity in middle age and future risk of dementia: a 27 year longitudinal population based study. BMJ 330, 1360.

[5] Qiu C, von Strauss E, Fastbom J, Winblad B, Fratiglioni $\mathrm{L}$ (2003) Low blood pressure and risk of dementia in the Kungsholmen project: a 6-year follow-up study. Arch Neurol 60, 223-228. 
[6] Grobe JL, Xu D, Sigmund CD (2008) An intracellular reninangiotensin system in neurons: fact, hypothesis, or fantasy. Physiology (Bethesda) 23, 187-193.

[7] Kumar A, Rassoli A, Raizada MK (1988) Angiotensinogen gene expression in neuronal and glial cells in primary cultures of rat brain. J Neurosci Res 19, 287-290.

[8] von Bohlen und Halbach O, Albrecht D (2006) The CNS renin-angiotensin system. Cell Tissue Res 326, 599-616.

[9] Phillips MI, de Oliveira EM (2008) Brain renin angiotensin in disease. J Mol Med 86, 715-722.

[10] Arregui A, Perry EK, Rossor M, Tomlinson BE (1982) Angiotensin converting enzyme in Alzheimer's disease increased activity in caudate nucleus and cortical areas. $J$ Neurochem 38, 1490-1492.

[11] He M, Ohrui T, Maruyama M, Tomita N, Nakayama K, Higuchi M, Furukawa K, Arai H (2006) ACE activity in CSF of patients with mild cognitive impairment and Alzheimer disease. Neurology 67, 1309-1310.

[12] Kehoe PG, Katzov H, Andreasen N, Gatz M, Wilcock GK, Cairns NJ, Palmgren J, de Faire U, Brookes AJ, Pedersen NL, Blennow K, Prince JA (2004) Common variants of ACE contribute to variable age-at-onset of Alzheimer's disease. Hum Genet 114, 478-483.

[13] Miners S, Ashby E, Baig S, Harrison R, Tayler H, Speedy E, Prince JA, Love S, Kehoe PG (2009) Angiotensin-converting enzyme levels and activity in Alzheimer's disease: differences in brain and CSF ACE and association with ACE1 genotypes. Am J Transl Res 1, 163-177.

[14] Savaskan E, Hock C, Olivieri G, Bruttel S, Rosenberg C, Hulette C, Muller-Spahn F (2001) Cortical alterations of angiotensin converting enzyme, angiotensin II and AT1 receptor in Alzheimer's dementia. Neurobiol Aging 22, 541-546.

[15] Ge J, Barnes NM (1996) Alterations in angiotensin AT1 and AT2 receptor subtype levels in brain regions from patients with neurodegenerative disorders. Eur J Pharmacol 297, 299-306.

[16] Khachaturian AS, Zandi PP, Lyketsos CG, Hayden KM, Skoog I, Norton MC, Tschanz JT, Mayer LS, Welsh-Bohmer KA, Breitner JC (2006) Antihypertensive medication use and incident Alzheimer disease: the Cache County Study. Arch Neurol 63, 686-692.

[17] Bjorkhem I, Meaney S (2004) Brain cholesterol: long secret life behind a barrier. Arterioscler Thromb Vasc Biol 24, 806815 .

[18] Sparks DL (2008) The early and ongoing experience with the cholesterol-fed rabbit as a model of Alzheimer's disease: the old, the new and the pilot. J Alzheimers Dis 15, 641-656.

[19] Rahman A, Akterin S, Flores-Morales A, Crisby M, Kivipelto M, Schultzberg M, Cedazo-Minguez A (2005) High cholesterol diet induces tau hyperphosphorylation in apolipoprotein E deficient mice. FEBS Lett 579, 6411-6416.

[20] Mateos L, Akterin S, Gil-Bea FJ, Spulber S, Rahman A, Bjorkhem I, Schultzberg M, Flores-Morales A, CedazoMinguez A (2009) Activity-regulated cytoskeleton-associated protein in rodent brain is down-regulated by high fat diet in vivo and by 27-hydroxycholesterol in vitro. Brain Pathol 19, 69-80.

[21] Bjorkhem I, Lutjohann D, Breuer O, Sakinis A, Wennmalm A (1997) Importance of a novel oxidative mechanism for elimination of brain cholesterol. Turnover of cholesterol and 24(S)-hydroxycholesterol in rat brain as measured with $18 \mathrm{O} 2$ techniques in vivo and in vitro. J Biol Chem 272, 30178-30184.

[22] Bjorkhem I, Cedazo-Minguez A, Leoni V, Meaney S (2009) Oxysterols and neurodegenerative diseases. Mol Aspects Med 30, 171-179.
[23] Bjorkhem I, Heverin M, Leoni V, Meaney S, Diczfalusy U (2006) Oxysterols and Alzheimer's disease. Acta Neurol Scand Suppl 185, 43-49.

[24] Heverin M, Meaney S, Lutjohann D, Diczfalusy U, Wahren J, Bjorkhem I (2005) Crossing the barrier: net flux of 27hydroxycholesterol into the human brain. J Lipid Res $\mathbf{4 6}$, 1047-1052.

[25] Heverin M, Bogdanovic N, Lutjohann D, Bayer T, Pikuleva I, Bretillon L, Diczfalusy U, Winblad B, Bjorkhem I (2004) Changes in the levels of cerebral and extracerebral sterols in the brain of patients with Alzheimer's disease. J Lipid Res $\mathbf{4 5}$, 186-193.

[26] Bjorkhem I (2009) Are side-chain oxidized oxysterols regulators also in vivo? J Lipid Res 50 Suppl, S213-S218.

[27] Winblad B, Palmer K, Kivipelto M, Jelic V, Fratiglioni L, Wahlund LO, Nordberg A, Backman L, Albert M, Almkvist $\mathrm{O}$, Arai H, Basun H, Blennow K, de Leon M, DeCarli C, Erkinjuntti T, Giacobini E, Graff C, Hardy J, Jack C, Jorm A, Ritchie K, van Duijn C, Visser P, Petersen RC (2004) Mild cognitive impairment - beyond controversies, towards a consensus: report of the International Working Group on Mild Cognitive Impairment. J Intern Med 256, 240-246.

[28] Leoni V, Masterman T, Mousavi FS, Wretlind B, Wahlund LO, Diczfalusy U, Hillert J, Bjorkhem I (2004) Diagnostic use of cerebral and extracerebral oxysterols. Clin Chem Lab Med 42, 186-191.

[29] Cedazo-Minguez A, Hamker U, Meske V, Veh RW, Hellweg R, Jacobi C, Albert F, Cowburn RF, Ohm TG (2001) Regulation of apolipoprotein $\mathrm{E}$ secretion in rat primary hippocampal astrocyte cultures. Neuroscience 105, 651-661.

[30] Yang G, Gray TS, Sigmund CD, Cassell MD (1999) The angiotensinogen gene is expressed in both astrocytes and neurons in murine central nervous system. Brain Res $\mathbf{8 1 7}$, 123-131.

[31] Leoni V, Shafaati M, Salomon A, Kivipelto M, Bjorkhem I, Wahlund LO (2006) Are the CSF levels of 24S-hydroxycholesterol a sensitive biomarker for mild cognitive impairment? Neurosci Lett 397, 83-87.

[32] Ghribi O (2008) Potential mechanisms linking cholesterol to Alzheimer's disease-like pathology in rabbit brain, hippocampal organotypic slices, and skeletal muscle. J Alzheimers Dis 15, 673-684.

[33] Greenwood CE, Winocur G (2005) High-fat diets, insulin resistance and declining cognitive function. Neurobiol Aging 26 Suppl 1, 42-45.

[34] Yehuda S, Rabinovitz S, Mostofsky DI (2005) Mediation of cognitive function by high fat diet following stress and inflammation. Nutr Neurosci 8, 309-315.

[35] Jansen PJ, Lutjohann D, Thelen KM, von Bergmann K, van Leuven F, Ramaekers FC, Monique M (2009) Absence of ApoE upregulates murine brain ApoD and ABCA1 levels, but does not affect brain sterol levels, while human ApoE3 and human ApoE4 upregulate brain cholesterol precursor levels. J Alzheimers Dis 18, 319-329.

[36] Inaba S, Iwai M, Furuno M, Tomono Y, Kanno H, Senba I, Okayama H, Mogi M, Higaki J, Horiuchi M (2009) Continuous activation of renin-angiotensin system impairs cognitive function in renin/angiotensinogen transgenic mice. Hypertension 53, 356-362.

[37] Inaba S, Iwai M, Tomono Y, Senba I, Furuno M, Kanno H, Okayama H, Mogi M, Higaki J, Horiuchi M (2009) Exaggeration of focal cerebral ischemia in transgenic mice carrying human renin and human angiotensinogen genes. Stroke 40, 597-603. 
[38] Saavedra JM (2005) Brain angiotensin II: new developments, unanswered questions and therapeutic opportunities. Cell Mol Neurobiol 25, 485-512.

[39] Phillips MI (1987) Functions of angiotensin in the central nervous system. Annu Rev Physiol 49, 413-435.

[40] Suzuki Y, Ruiz-Ortega M, Lorenzo O, Ruperez M, Esteban V, Egido J (2003) Inflammation and angiotensin II. Int J Biochem Cell Biol 35, 881-900.

[41] Wosik K, Cayrol R, Dodelet-Devillers A, Berthelet F, Bernard M, Moumdjian R, Bouthillier A, Reudelhuber TL, Prat A (2007) Angiotensin II controls occludin function and is required for blood brain barrier maintenance: relevance to multiple sclerosis. J Neurosci 27, 9032-9042.

[42] Schelman WR, Andres R, Ferguson P, Orr B, Kang E, Weyhenmeyer JA (2004) Angiotensin II attenuates NMDA receptor-mediated neuronal cell death and prevents the associated reduction in Bcl-2 expression. Brain Res Mol Brain Res 128, 20-29.

[43] Qiu C, Winblad B, Fratiglioni L (2005) The age-dependent relation of blood pressure to cognitive function and dementia. Lancet Neurol 4, 487-499.

[44] Birkenhager WH, Forette F, Seux ML, Wang JG, Staessen JA (2001) Blood pressure, cognitive functions, and prevention of dementias in older patients with hypertension. Arch Intern Med 161, 152-156.

[45] Gard PR, Rusted JM (2004) Angiotensin and Alzheimer's disease: therapeutic prospects. Expert Rev Neurother 4, 87-96.

[46] Nikolova JG, Getova DP, Nikolov FP (2000) Effects of ACEinhibitors on learning and memory processes in rats. Folia Med (Plovdiv) 42, 47-51.

[47] Raghavendra V, Chopra K, Kulkarni SK (2001) Comparative studies on the memory-enhancing actions of captopril and losartan in mice using inhibitory shock avoidance paradigm. Neuropeptides 35, 65-69.

[48] Hamai M, Iwai M, Ide A, Tomochika H, Tomono Y, Mogi M, Horiuchi M (2006) Comparison of inhibitory action of candesartan and enalapril on brain ischemia through inhibition of oxidative stress. Neuropharmacology 51, 822-828.

[49] Iwai M, Horiuchi M (2009) Devil and angel in the reninangiotensin system: ACE-angiotensin II-AT1 receptor axis vs. ACE2-angiotensin-(1-7)-Mas receptor axis. Hypertens Res 32, 533-536.

[50] Craft S (2009) The role of metabolic disorders in Alzheimer disease and vascular dementia: two roads converged. Arch Neurol 66, 300-305. 